\title{
Osteopontin Is Involved in the Initiation of Cutaneous Contact Hypersensitivity by Inducing Langerhans and Dendritic Cell Migration to Lymph Nodes
}

\author{
J.M. Weiss, ${ }^{1}$ A.C. Renkl, ${ }^{1}$ C.S. Maier, ${ }^{1}$ M. Kimmig, ${ }^{1}$ L. Liaw, ${ }^{4}$ \\ T. Ahrens, ${ }^{1}$ S. Kon, ${ }^{3}$ M. Maeda, ${ }^{3}$ H. Hotta, ${ }^{2}$ T. Uede, ${ }^{2}$ and J.C. Simon ${ }^{1}$
}

${ }^{1}$ Department of Dermatology, University of Freiburg, D-79104 Freiburg, Germany
${ }^{2}$ Institute for Genetic Medicine, Hokkaido University, Sapporo 060-0815, Japan
${ }^{3}$ Immuno-Biological Laboratory, Fujioka-shi, Gunma 375-0005, Japan
${ }^{4}$ Center for Molecular Medicine, Maine Medical Center Research Institute, Portland, ME 04074

\begin{abstract}
Osteopontin (OPN) is a chemotactic protein that attracts immune cells, to inflammatory sites. The sensitization phase of allergic cutaneous contact hypersensitivity (CHS) requires the migration of Langerhans cells/dendritic cells (LCs/DCs) from skin to draining lymph nodes. Characterizing OPN function for LC/DC migration we found upregulated OPN expression in hapten sensitized skin and draining lymph nodes. OPN induces chemotactic LC/DC migration, initiates their emigration from the epidermis, and attracts LCs/DCs to draining lymph nodes by interacting with CD44 and $\alpha \mathrm{v}$ integrin. Furthermore, OPN-deficient mice have a significantly reduced CHS response that correlates with an impaired ability of OPN-deficient mice to attract LCs/DCs to draining lymph nodes. In conclusion, OPN is an important factor in the initiation of CHS by guiding LCs/DCs from skin into lymphatic organs.
\end{abstract}

Key words: dendritic cells $\bullet$ Langerhans cells $\bullet$ integrins $\bullet$ CD44 $\bullet$ osteopontin

\section{Introduction}

Dendritic cells $(\mathrm{DCs})^{*}$ are a special subset of potent antigen-presenting cells that are central in the induction of cellular immune reactions against various antigens, among them infectious agents, tumor associated antigens, foreign proteins, and chemical haptens (for reviews, see references $1-3)$. Immature cells of the DC lineage are situated in nonlymphoid tissues of many organs (2). For example Langerhans cells (LCs), the DCs of the epidermis, are situated in the suprabasal layers of the epidermis $(2,4)$. Upon antigenic stimulation in the presence of inflammatory mediators these LCs/DCs mature, process antigen, and become migratory (for a review, see references 1-3). They enter secondary lymphoid organs where they use these newly acquired capabilities to induce $\mathrm{T}$ cell-dependent immune responses $(1,3,5)$. Although a variety of factors involved

J.M. Weiss and A.C. Renkl contributed equally to this work.

Address correspondence to Johannes M. Weiss, Department of Dermatology, University of Freiburg, Hauptstrasse 7, D-79104 Freiburg, Germany. Phone: 49-761-270-6701; Fax: 49-761-270-6829; E-mail: weiss@haut.ukl.uni-freiburg.de

*Abbreviations used in this paper: ANOVA, analysis of variance; CHS, contact hypersensitivity; DC, dendritic cell; ECM, extracellular matrix; LC, Langerhans cell; OPN, osteopontin; TNCB, Trinitro-chloro-benzene. have been characterized, migration of LCs/DCs between peripheral organs such as the skin and secondary lymphatic tissues is only beginning to be understood. However, firm knowledge of the DC migratory process is essential for clinical application of DCs in tumor and antimicrobial vaccination protocols or for the attenuation of allergic responses. Easy accessibility of epidermal LCs has made the skin the preferred organ to study DC migration in different models $(2,6,7)$.

Osteopontin (OPN) is a secreted acidic phosphoprotein with functions in bone remodeling, tumor metastasis, and host defense $(8,9)$. A variety of immunological disorders were shown to be associated with high OPN expression, e.g., by activated lymphocytes and macrophages (10-13). Initially, OPN (eta1) was found to be expressed after nonspecific activation in $\mathrm{T}$ cells and a subset of natural killer cells $(11,13)$. In murine immune deficiency syndrome (MIDS), elevated levels of OPN were detected in spleens and lymph nodes of infected animals (10). Interestingly, OPN is involved in delayed type hypersensitivity reactions against $M Y$ cobacterium tuberculosis and OPN is detectable in macrophages, lymphocytes, and the extracellular matrix (ECM) in diseased tissue with granulomatous pathology $(9,14,15)$. 
Mice lacking OPN have an attenuated host resistance against Mycobacterium bovis (16). Further, mice deficient in OPN have a severely impaired cell-mediated immunity against herpes simplex virus-type 1 or Listeria monocytogenes and do not form sarcoid-type granulomas (17).

OPN may act in both a monomeric as well as in a polymeric form (18). The polymeric form interacts mainly with ECM components like collagens $(18,19)$ and fibronectin $(18,20)$. Thus, OPN exerts dual functions as a chemoattractive cytokine and as an ECM component initiating cell-ECM interactions. In its function as a cytokine, OPN attracts monocytes to sites of inflammation, stimulates chemotactic endothelial cell migration, and attracts smooth muscle cells $(14,21,22)$.

OPN, like fibronectin, contains a GRGDS integrin binding domain thereby promoting adhesion of cells expressing $\alpha v \beta 3, \alpha v \beta 1$, and $\alpha v \beta 5$ integrins (22). The $\alpha v \beta 3$ integrin is particularly important for supporting OPNinduced cell migration in smooth muscle cells and endothelial cells $(21,22)$. CD 44 has been characterized as another receptor stimulating OPN-induced migration (23). OPN stimulated cell migration in CD44-transfected A31 murine fibroblasts and in pancreatic carcinoma cell lines transfected with CD44 variants encoding CD44 isoforms (23, 24).

Our investigation was designed to functionally characterize DC-OPN interactions focusing on two putative OPN receptors that mediate OPN-induced cell migration, CD44 and $\alpha v \beta 3$. We have previously shown that CD44 is differentially modulated during LC/DC activation and participates in their migration out of the skin, their adhesion to the paracortical $\mathrm{T}$ cell zones of peripheral lymph nodes, and in the LC-dependent sensitization phase of contact hypersensitivity (CHS) (25). However, the ligands responsible for the described CD44 functions remained uncharacterized.

Here we demonstrate that OPN is crucially involved in DC migration from the skin to regional lymph nodes during the sensitization phase of CHS. OPN interacts with both CD44 and $\alpha \mathrm{v}$ on DC, thereby inducing chemotactic DC migration. Further, we show that OPN-deficient mice are compromised in their ability to attract LCs/DCs to draining lymphatic organs and have an impaired CHS response to Trinitro-chloro-benzene (TNCB).

\section{Materials and Methods}

\section{Media and Chemicals}

Complete-RPMI 1640 (c-RPMI; GIBCO BRL) was supplemented with 10\% heat-inactivated FCS (GIBCO BRL), 25 mM HEPES (Sigma-Aldrich), $1 \mathrm{mM}$ nonessential amino acids (GIBCO BRL), 2 mM L-glutamine (GIBCO BRL), 1 nM 2-mercaptoethanol (Sigma-Aldrich), penicillin, and streptomycin, both $90 \mu \mathrm{g} /$ liter (GIBCO BRL).

\section{GST-Fusion Proteins}

GST-OPN fusion proteins were synthesized based on the published murine OPN cDNA sequence (26) as described previously (27).

\section{OPN-null Mutant Mice}

The mice lacking the functional OPN gene (spp1) were described previously (28). Mice were crossed to the C57BL/6 background. For all experiments, OPN mutant mice and their wildtype littermates in the sixth generation of backcrossing were used.

\section{Cultures}

Murine DCs were generated as described $(29,30)$, with minor alterations. Bone marrow was harvested from the tibia and fibula of C57BL/6 mice. The cells were resuspended at $10^{6}$ cells $/ \mathrm{ml}$ cRPMI-1640 (GIBCO BRL) with $40 \mathrm{ng} / \mathrm{ml}$ recombinant murine GM-CSF (PromoCell) and $10 \mathrm{ng} / \mathrm{ml}$ recombinant murine IL-4 (PromoCell). Cells were cultured at 1-ml aliquots in 24-well culture plates (Greiner). Cells were fed on days 3 and 5 of culture, by replacing half the medium in each well with fresh cRPMI containing GM-CSF and IL-4. Loosely adherent cells, including DCs were harvested by gentle pipetting, on day 6 of culture. Cells were washed once and resuspended at $5 \times 10^{5}$ cells $/ \mathrm{ml}$ in cRPMI. $8 \mathrm{ml}$ of the cell suspension were underlayed with $2 \mathrm{ml}$ 14.5\% Metrizamide (Boehringer) in a 14- $\mathrm{ml}$ conical bottomed tube (Becton Dickinson) and centrifuged at room temperature $\left(22^{\circ} \mathrm{C}\right)$ for $20 \mathrm{~min}$ at $600 \mathrm{~g}$. The low buoyant density cells were collected, washed twice, and resuspended for use. These suspensions that were used in all following experiments contained routinely $>80 \%$ cells expressing highly Iab, CD11c, B7-1, and B7-2 and were designated DCs (30).

\section{Immunostaining and Flow Cytometry}

Cells were stained as described (25) with one of the following mAbs: murine-specific anti- $\alpha \mathrm{v}$ (anti-CD51, clone H9.2B8, Armenian hamster IgG, biotinylated; BD PharMingen), anti- $\beta 3$ (CD61, Clone 2C9.G2, Armenian hamster IgG, biotinylated; BD PharMingen), anti-CD44 (IM7, rat IgG, PE labeled), or appropriate isotype control (clone 8C1, Armenian hamster IgG, biotinylated labeled, or rat IgG [R3-34], PE labeled; all BD PharMingen). 7-aminoactinomycin D (7-ADD, $2.5 \mu \mathrm{g} / \mathrm{ml}$; Sigma-Aldrich) was added to exclude dead cells by appropriate gating. CELLQuest ${ }^{\mathrm{TM}}$ software (Becton Dickinson) was applied using a FACScan ${ }^{\mathrm{TM}}$ (Becton Dickinson) to analyze $10^{4}$ viable cells from each sample.

\section{Full-thickness Skin Organ Culture}

Skin cultures and immunohistochemical staining were performed as described previously (25). In brief, 4-mm punch biopsies containing human dermis and epidermis were placed into 25$\mathrm{mm}$ tissue culture inserts with a $0.02-\mu \mathrm{m}$ anapore membrane (Nunc) and incubated in 6-well tissue culture plates filled with C-RPMI up to the dermal-epidermal junction. Cultures were terminated as indicated and samples shock-frozen in $\mathrm{N}_{2}$. Sections $(5 \mu \mathrm{m})$ were prepared with a Cryocut 1800 (Leica). First, sections were overlaid with mAb against OPN (10A16, mouse IgG, Immunobiological Laboratory [31]) for $30 \mathrm{~min}$, room temperature, followed by a Cy3-conjugated goat-F(ab) ${ }_{2}$-anti-mouse IgG $(\mathrm{H}+\mathrm{L})$ antibody for $1 \mathrm{~h}$, room temperature. In a second step, sections were incubated with FITC-conjugated anti-CD1a mAb for $30 \mathrm{~min}$ (room temperature). Serial sections of biopsies were stained with hemalum to obtain bright field images. Staining was evaluated with a ZEISS Axioskop, equipped with a MC100 camera system.

\section{In Vitro DC Migration Assay}

In vitro DC migration was evaluated using a 48 -well micro chemotaxis chamber (Costar) as described previously (32). 27 
$\mu l$ of chemoattractant at the indicated concentrations in HBSS with or without $\mathrm{Ca}^{2+}, \mathrm{Mg}^{2+}$, were added to the lower chamber. A polycarbonate-filter, pore size $8 \mu \mathrm{m}$ (Costar) was layered onto the wells, covered by a silicon gasket followed by the top plate. For migration of DCs, $50 \mu \mathrm{l}$ of cell suspension $\left(10^{6}\right.$ cells/ml HBSS without $\mathrm{Ca}^{2+}, \mathrm{Mg}^{2+}$ ) were added to the upper chamber. After the incubation, at $37^{\circ} \mathrm{C}, 5 \% \mathrm{CO}_{2}$ for $4 \mathrm{~h}$, filters were removed and stained with Diff-Quick (Baxter). Cells on the upper filter surface were removed, cells that had migrated to the filter bottom quantified counting four ocular grids $(40 \times)$. Results are expressed as mean number of migrated cells $/ \mathrm{mm}^{2} \pm \mathrm{SD}$ of four chambers. Each experiment was performed in triplicate. For one set of experiments, filters were coated with $100 \mu \mathrm{g} / \mathrm{ml}$ gelatine in $0.1 \%$ acetic acid at $37^{\circ} \mathrm{C}$ overnight (Sigma-Aldrich). For $\mathrm{mAb}$ blocking experiments, DCs were preincubated with the mAbs IM7 (murine pan CD44, rat IgG2b; BD PharMingen), KM81 (murine pan CD44, rat IgG2a, TIB-241; American Type Culture Collection), anti-RMV7 (against $\alpha \mathrm{v}$ integrin, rat IgG2c, supplied by Drs. Yagita and Okumura, Juntendo University School of Medicine, Tokyo, Japan [33]), or isotype control mAb Y13259 (rat IgG1; American Type Culture Collection) at $10 \mu \mathrm{g} /$ $\mathrm{ml}$ for $30 \mathrm{~min}$ at $37^{\circ} \mathrm{C}, 5 \% \mathrm{CO}_{2}$.

\section{In Vivo LC/DC Migration Assays}

LC Migration in Ear Pinnae. $20 \mu \mathrm{l}$ OPN $(50 \mu \mathrm{g} / \mathrm{ml}$ in PBS) were injected into the ear pinnae of mice. For blocking experiments anti-CD44 mAb (IM7 or KM81) anti- $\alpha \mathrm{v}$ integrin $\mathrm{mAb}$ (RMV7) or isotype control mAb Y13-259 (rat IgG1; American Type Culture Collection) were coinjected. After $48 \mathrm{~h}$ animals were killed and ears were cut off at the base with scissors. Epidermal sheets were prepared as described (34). In brief, ears were spread out on a Petri dish, then split into dorsal and ventral halves with forceps. The dorsal halves were treated with $0.5 \%$ dispase (Boehringer) at $37^{\circ} \mathrm{C}$ for $1.5 \mathrm{~h}$ on a shaker. Epidermis was split from dermis and epidermal sheets were washed with PBS. After fixation in 4\% formaldehyde with cacodylic acid buffer epidermal sheets were stained by ATPase histochemistry as described (34). The number of dark brown staining LCs in the epidermis was evaluated by counting four high power grids. Results are shown as number of $\mathrm{LC} / \mathrm{mm}^{2} \pm \mathrm{SD}$ in sheets from four ears.

Analysis of Lymph Node DCs after FITC Skin Painting. The number of lymph node DCs after FITC skin painting was analyzed as described previously with minor alterations (35). In brief, FITC (Sigma-Aldrich) was dissolved in a 50:50 ( $\mathrm{vol} / \mathrm{vol}$ ) acetone dibutylphtalate (BDH) mixture just before application. Mice were painted on the shaved abdomen and thorax with 0.4 $\mathrm{ml}$ of $5 \mathrm{mg} / \mathrm{ml}$ of FITC. Inguinal and axillary lymph nodes of one mouse were obtained after $48 \mathrm{~h}$, mechanically disaggregated, pooled, stained with an $\mathrm{PE}$ labeled $\mathrm{mAb}$ against mouse CD11c (clone 8L3, hamster IgG; BD PharMingen), and FITC double-positive cells were analyzed by a FACS ${ }^{\circledR}$ (Becton Dickinson).

DC Migration in OPN Mutant Mice. DCs were generated form wild-type littermates of OPN mutant mice, labeled as described above, and injected at 250,000 DCs in $30 \mu \mathrm{l}$ of PBS into each quadrant of the abdominal skin of wild-type or OPN mutant mice. Inguinal and axillary lymph nodes were obtained after $20 \mathrm{~h}$, mechanically disaggregated, pooled, stained with a PElabeled $\mathrm{mAb}$ against mouse CD11c (clone 8L3, hamster IgG; BD PharMingen) and CD11c, PKH2-GL ${ }^{\circledR}$ double-positive cells were analyzed by a FACS ${ }^{\circledR}$.

\section{CHS Assays}

6-wk-old female C57BL/6 OPN mutant mice or wild-type littermates were painted on their abdominal skin with $100 \mu$ l of $7 \%$ TNCB in acetone at day 0 (25). On day 5, mice were challenged by painting $10 \mu \mathrm{l} 1 \%$ TNCB on both sides of the ears. Ear thickness was measured with an engineer's micrometer (Mitutoyo) before and at 24 and $48 \mathrm{~h}$ after the challenge and ear swelling was calculated (25).

RNA Isolation, Reverse Transcription and PCR Amplification of Sensitized Skin and Skin Draining Lymph Nodes

Abdominal skin of C57BL/6 mice was painted with TNCB $(7 \%)$, or as a control with acetone, as described previously (25). Mice were killed at $6,12,24$, and $48 \mathrm{~h}$ after hapten application. Skin specimens and regional draining inguinal lymph nodes where obtained and immediately shock-frozen in liquid nitrogen, for later analysis by reverse transcription (RT)-PCR. Total cellular RNA from skin specimens and lymph nodes was extracted using Total RNA Rneasy ${ }^{\circledR}$ Kit according to the manufacturer's protocol (QIAGEN). OPN transcript-specific primers were synthesized based on the published sequences for murine OPN (26): OPN upper primer 5'-ATTTGCTTTTGCCTGTTTGG-3' (starting at position +16 of the published cDNA of Craig et al. [26]), OPN lower primer 5'-CCTTTCCGTTGTTGTCCTGA-3' (position +603 ). The PCR resulting in amplification of a 606-bp fragment was performed at $94^{\circ} \mathrm{C}$ for $60 \mathrm{~s}, 50^{\circ} \mathrm{C}$ for $60 \mathrm{~s}$, and $72^{\circ} \mathrm{C}$ for $60 \mathrm{~s}$ for a total of 35 cycles. As a control, RT-PCR experiments using murine $\beta$-actin primers $5^{\prime}$-GACTACCTCATGAAGATCCT $-3^{\prime}$ (position 639 of the cDNA published previously (36) and 5'-ATCCACATCTGCTGGAAGGT-3' (position 1,131) amplifying a 511-bp cDNA fragment were performed $\left(94^{\circ} \mathrm{C}\right.$ for $60 \mathrm{~s}, 53^{\circ} \mathrm{C}$ for $60 \mathrm{~s}$, and $72^{\circ} \mathrm{C}$ for $60 \mathrm{~s}$ for a total of 25 cycles). Amplified fragments were separated in parallel with the coamplified actin reference fragment by electrophoresis in 2\% agarose (GIBCO). Fluorescence was visualized at $312 \mathrm{~nm}$ UV, digitalized with a high-resolution CCD camera (Herolab), and the individual fragments were quantitated and relative intensity was analyzed with the E.A.S.Y. ${ }^{\circledR} \mathrm{Win} 32$-software (Herolab).

\section{Immunohistochemistry of Skin Draining Lymph Nodes}

Abdominal skin of C57BL/6 mice was painted with TNCB $(7 \%)$, or as a control with acetone, as described previously (25). Mice were killed at 0, 24, and $48 \mathrm{~h}$ after hapten application. Regional skin draining inguinal lymph nodes where obtained and immediately shock-frozen in liquid nitrogen. Skin draining lymph nodes were obtained after TNCB skin paining as described above. Specimens were embedded in Optimum Cutting Medium (Miles Inc.) and sections $(5 \mu \mathrm{m})$ were prepared with a Cryocut 1800 (Leica). Air-dried, acetone-fixed frozen sections were stained for OPN using a four-step immunohistochemical staining protocol (ABC-technique; Dako): (a) primary anti-OPN $\mathrm{mAb} 2.2$ (rat anti-mouse) (37); (b) biotin-conjugated rabbit antirat $\operatorname{IgG}$; (c) peroxides conjugated streptavidin, and (d) Dako ${ }^{\circledR}$ 3-amino-9-ethyl carbazole (AEC) as chromogenic substrate. For CD3 staining biotinylated anti-CD3 $\mathrm{mAb}$ (rat anti-mouse; Dianova) was used. Staining was visualized with VECTASTAIN ${ }^{\circledR}$ ABC-AP Kit (Vector Laboratories) using Vector Blue Substrate Kit III (Vector Laboratories) as a chromogen. Control staining was performed by replacing the primary antibody with isotypematched control reagents. Staining was evaluated with a ZEISS Axioskop, equipped with a MC100 camera system. 


\section{Results}

OPN Is Upregulated in the Sensitization Phase of CHS. OPN has been shown to be a chemotactic factor that attracts inflammatory cells, such as monocytes and $\mathrm{T}$ cells to sites of inflammation $(14,17,38,39)$.

The sensitization phase of CHS crucially depends upon the migration of LCs from the epidermis to lymph nodes draining the skin. We speculated that OPN secreted e.g., by other inflammatory cells or endothelial cells could function to guide LCs from the epidermis to draining lymph nodes. To explore the expression of OPN during migration of human LCs from the epidermis we made use of an explant culture in which LCs move actively from the epidermis into dermis (25). Skin cryostat sections were stained by immunohistochemical double labeling using $\mathrm{mAb}$ against $\mathrm{CD} 1 \mathrm{a}$ or Lag mAb, specific for LCs (FITC, green) and OPN-specific mAb 10A16 (Cy3, red). At $24 \mathrm{~h}$ of skin culture OPN was strongly expressed in the dermis in the area of the papillary vascular plexus, most likely reflecting staining of dermal microvascular endothelial cells which highly express OPN (21; Fig. 1 A-D). LCs were found to migrate predominantly toward sites of high OPN expression forming cords in these areas (Fig. $1 \mathrm{~B}$ ) as shown previously $(25,40)$.

Our explant model mimics the migration process of LCs during the sensitization phase of allergic CHS. We therefore speculated that OPN is upregulated in skin during the sensitization phase of CHS. To test this hypothesis, the hapten TNCB was applied to the abdominal skin of C57BL/6 mice. Hapten painted abdominal skin, the regional skin draining axillary lymph nodes, and maxillary lymph nodes distant to the application site (as control) were analyzed for OPN mRNA expression using RT-PCR after 0, 6, 12, 24, and $48 \mathrm{~h}$ of TNCB application (Fig. 2, A-C). $12 \mathrm{~h}$ after TNCB painting, OPN mRNA was gradually upregulated in hapten treated skin (Fig. 2 A), peaking at $48 \mathrm{~h}$, in contrast to skin treated with the vehicle acetone alone. In parallel, OPN mRNA was strongly upregulated in axillary lymph nodes draining the skin (Fig. 2 B). In contrast, maxillary lymph nodes distant to the site of hapten application showed only a slight upregulation of OPN mRNA (Fig. 2 C). When immunohistochemistry of skin draining lymph nodes was performed with mAbs against OPN (mAb 2.2 [37]), lymph nodes of untreated (Fig. 2 D) or acetone painted mice (data not shown) showed little to no OPN specific staining. After $24 \mathrm{~h}$ following TNCB application, OPN staining was observed in draining lymph nodes which strongly increased up to $48 \mathrm{~h}$ (Fig. $2 \mathrm{D}$ ). OPN expression was predominantly located in the $\mathrm{T}$ cell areas of these lymph nodes as detected by staining of serial lymph node sections with anti-CD3 mAb (Fig. 2 D). No staining was found in lymph nodes of hapten-treated OPN-deficient mice (Fig. 2 D). These findings argue for an OPN function in the sensitization phase of CHS.

OPN Induces Chemotactic DC Migration In Vitro. Having demonstrated that OPN is expressed in skin and in lymph nodes draining that skin site during the sensitization phase of CHS we investigated whether OPN could func-
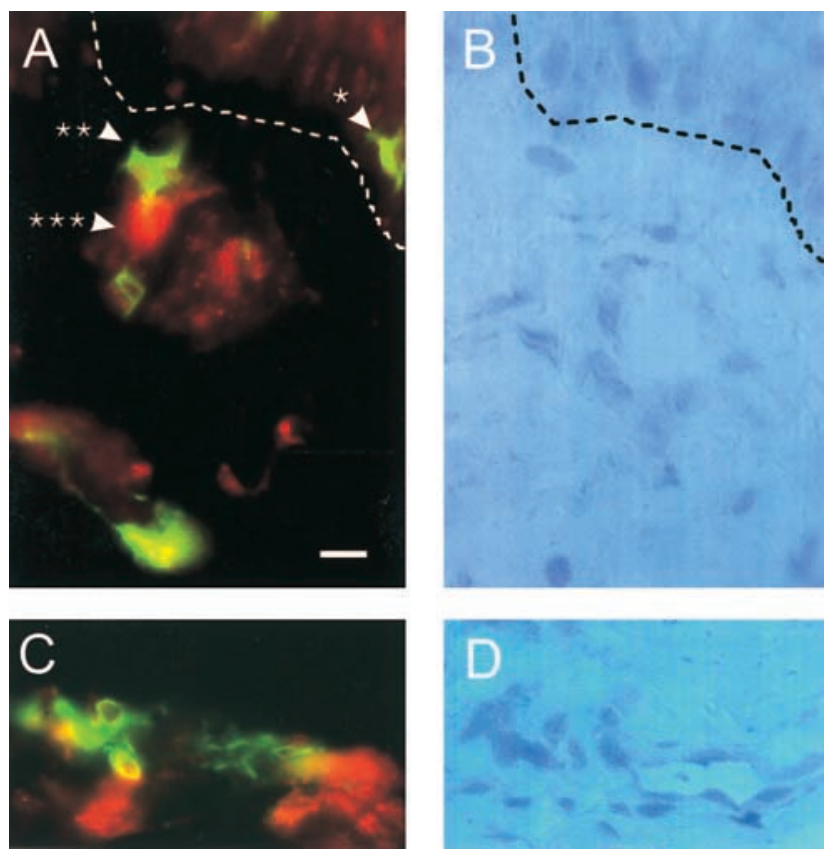

Figure 1. LCs migrate to sites of high OPN expression to form cords within the dermis. Cryosections of human skin cultured for $24 \mathrm{~h}$ were stained with anti-OPN mAb 10A16 followed by secondary Cy3-conjugated $\mathrm{F}(\mathrm{ab})$, goat-anti-mouse $\operatorname{IgG}(\mathrm{H}+\mathrm{L})$ to detect OPN (red), and FITC-conjugated anti-CD1a antibody (green). The dotted line marks the dermo-epidermal junction. (A) CD1a ${ }^{+}$LCs within the Epidermis (green $\left.{ }^{\star \star}\right)$. $\mathrm{CD} 1 \mathrm{a}^{+}$cells have migrated toward areas of high OPN expression (red $\left.{ }^{\star \star \star}\right)$ at the microvascular plexus of the papillary dermis. (B) Hemalum stained serial section of the same specimen. (C) CD1a ${ }^{+}$cells (green) form cords within the area of skin microvascular endothelial cells that highly express OPN (red). (D) Hemalum stained serial section of the same specimen. Same magnification in A, B, C, and D: bar $10 \mu \mathrm{m}$.

tion as a chemoattractant for murine LCs/DCs. Two putative OPN receptors CD44 and $\alpha \mathrm{v} \beta 3$ are functionally involved in OPN-mediated cell migration $(22,24)$. While $\alpha v \beta 3$-mediated migration requires divalent cations, CD44mediated OPN effects are $\mathrm{Ca}^{2+} / \mathrm{Mg}^{2+}$ independent $(22,23$, 24). We used recombinant GST-OPN to assess DC migration toward OPN in microchamber migration assays in the presence or absence of $\mathrm{Ca}^{2+} / \mathrm{Mg}^{2+}$. Addition of recombinant GST-OPN to the lower chamber induced DC migration in a dose-dependent manner in both settings. However, in the presence of $\mathrm{Ca}^{2+} / \mathrm{Mg}^{2+}$, up to $30 \%$ more DCs migrated toward OPN (Fig. 3). DCs migrated toward OPN in a manner resembling chemotaxis rather than chemokinesis because increasing concentrations of OPN in the upper chamber inhibited DC migration toward OPN (Table I). These findings indicate that OPN stimulates DC migration and that both $\mathrm{Ca}^{2+} / \mathrm{Mg}^{2+}$-dependent and -independent receptors are involved in DC migration toward OPN.

Expression of $\alpha v \beta 3$ Is Differentially Modulated during DC Maturation. Our chemotaxis experiments indicated that OPN-induced DC migration can be mediated by $\mathrm{Ca}^{2+} /$ $\mathrm{Mg}^{2+}$-dependent and -independent mechanisms. CD44 has been characterized as a migration-mediating OPN receptor acting in the absence of $\mathrm{Ca}^{2+} / \mathrm{Mg}^{2+}$ (23). Having previously demonstrated the importance of CD44 for DC func- 

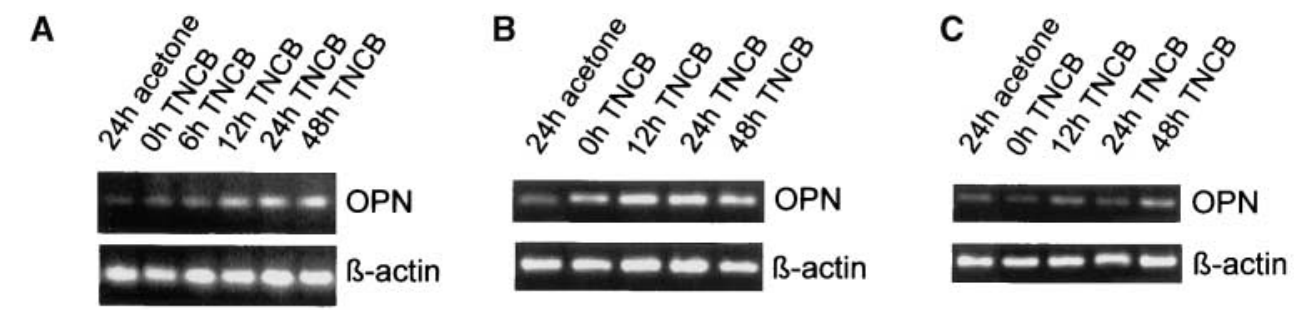

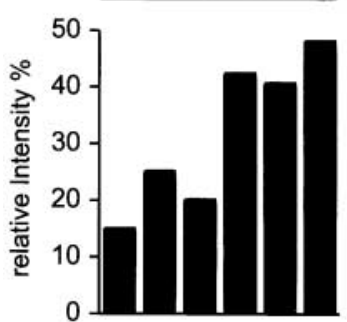

skin

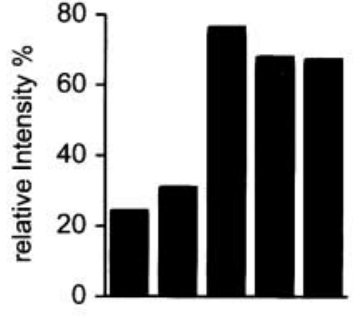

axillary lymph node

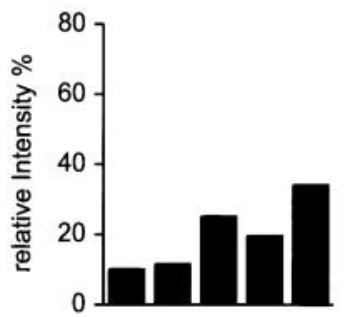

maxillary lymph node

D

\section{$+/+$ Oh anti-OPN}

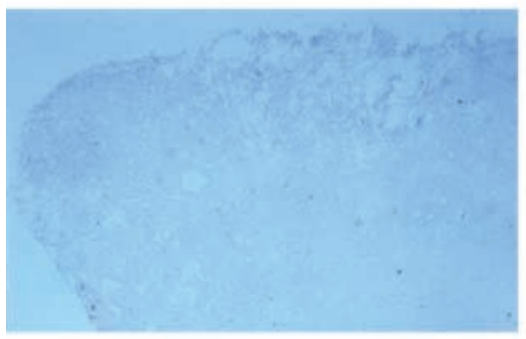

$+/+48 \mathrm{~h}$ anti-OPN

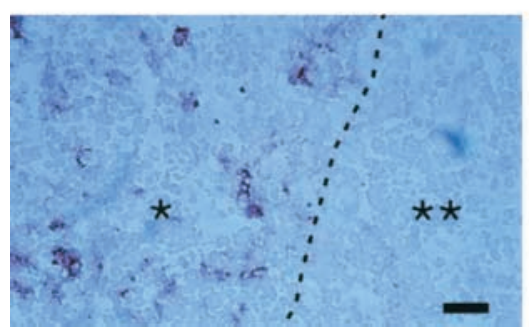

$+/+24 \mathrm{~h}$ anti-OPN

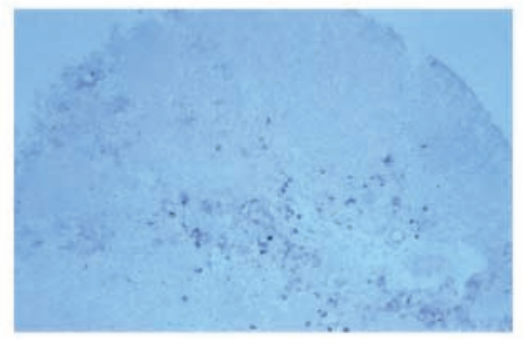

$-/-48 \mathrm{~h}$ anti-OPN

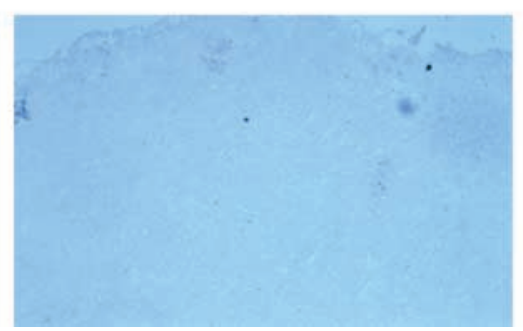

$+/+48 \mathrm{~h}$ anti-OPN

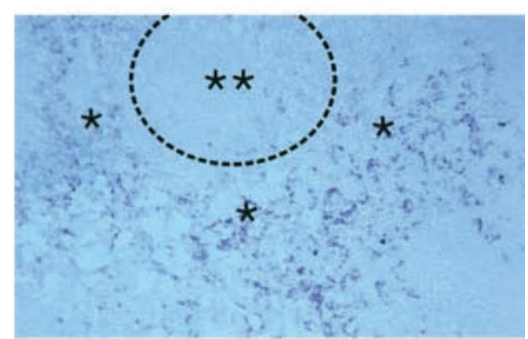

$+/+\quad 48 \mathrm{~h}$ anti-CD3

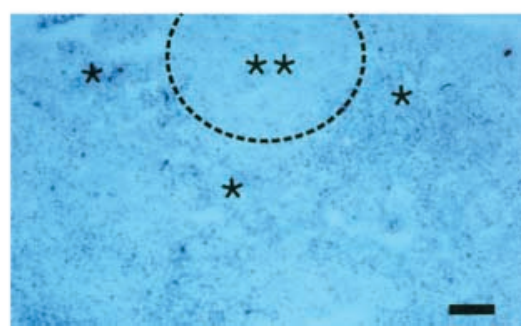

Figure 2. OPN is upregulated in skin and lymph nodes during CHS TNCB or acetone was applied to abdominal skin of C57BL/6 mice. Mice were killed at the indicated time points and skin specimens (A) from the haptenized site and axillary lymph nodes draining this skin site (B) or distant maxillary (C) lymph nodes were collected and subjected to RT-PCR with OPN specific primers as described in Materials and Methods. Percent relative intensity of the OPN mRNA compared with $\beta$-actin control was calculated with E.A.S.Y. ${ }^{\circledR}$ Win32-software. (D) TNCB was applied to abdominal skin of C57BL/6 mice. Immunohistochemical staining of cryosections with an antibody against OPN or CD3 of skin draining axillary lymph nodes from OPN deficient $(-/-)$ and wild-type $(+/+)$ C57BL/6 mice at the indicated time points after TNCB application to the abdominal skin. Top row: upregulation of OPN expression from 0 to $48 \mathrm{~h}$. Bottom row left: higher magnification of OPN expression at $48 \mathrm{~h}$. Bottom row middle: staining of skin draining axillary lymph nodes from OPN-deficient $(-/-)$ mouse with $\mathrm{mAb}$ against OPN. Bottom row right: staining with an antibody against CD3 of a serial section of the lymph node specimen taken at $48 \mathrm{~h}$ after TNCB application (top row right), ${ }^{*} \mathrm{~T}$ cell areas, ${ }^{\star *} \mathrm{~B}$ cell follicle. Magnification, bar $60 \mu \mathrm{m}$, except bottom left (48 h) bar $20 \mu \mathrm{m}$. OPN was visualized with brown, CD3 with blue chromogen as described in Materials and Methods.

tion during the sensitization phase of CHS (25) we now investigated the expression of the $\mathrm{Ca}^{2+} / \mathrm{Mg}^{2+}$-dependent OPN receptor $\alpha v \beta 3$ on DCs. DCs were generated from bone marrow culture and analyzed by FACS ${ }^{\circledR}$ (DC purity $>80 \%$ by definition of high expression of Iab, CD11c, B7-1, and B7-2 in FACS ${ }^{\circledR}$ analysis [30]). Immature DCs from day 6 bone marrow-DC cultures expressed both $\alpha v \beta 3$ (CD51/CD61; Fig. 4, A and B) and CD44 (Fig. 4 C). Upon maturation in bone marrow-DC cultures $\alpha v \beta 3$ expression was gradually upregulated from day 6 to 8 while CD44 was consistently expressed (Fig. 4, A-C). Taken together these results support the notion that the two OPN receptors $\alpha v \beta 3$ and CD44 are expressed on murine DCs. 


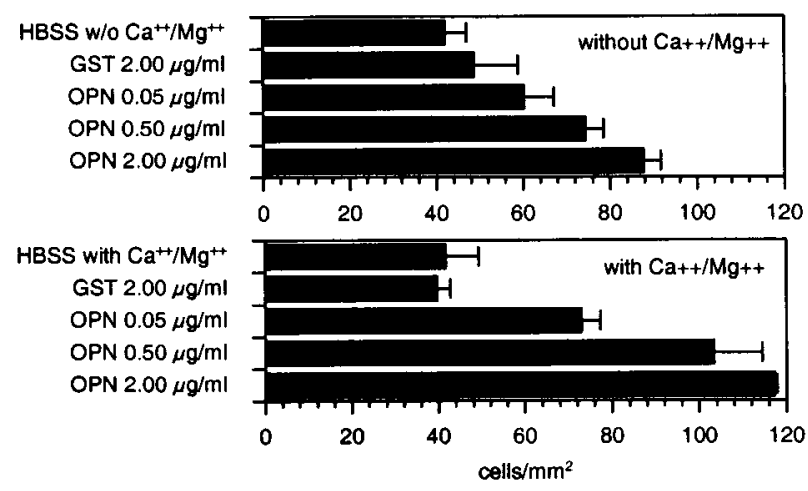

Figure 3. DCs migrate toward OPN in a dose-dependent manner in the presence or absence of divalent cations. Mouse DC $\left(10^{6}\right.$ cells $)$ were placed into the upper chambers of modified Boyden chambers as described in Materials and Methods. GST control protein $(2 \mu \mathrm{g} / \mathrm{ml})$ or the indicated concentrations of GST-OPN were added to the lower chamber. Assays were performed in HBSS without $\mathrm{Ca}^{2+} / \mathrm{Mg}^{++}$(A) or with $\mathrm{Ca}^{2+} / \mathrm{Mg}^{++}$(B). Data are shown as cells $/ \mathrm{mm}^{2} \pm \mathrm{SD}$ of four chambers.

Both Anti-CD44 and $\alpha v \beta 3 \mathrm{mAbs}$ Block OPN-induced DC Migration. Having identified two putative OPN receptors, CD44 and $\alpha v \beta 3$ on DCs, we next sought to determine their functional role for OPN-mediated DC migration. DCs were preincubated with mAbs against $\alpha \mathrm{v}$ (RMV7), anti-CD44 (IM7 or KM81), or appropriate control $\mathrm{mAb}$. Chemotaxis-chamber experiments were then performed in the presence or absence of divalent cations (Fig. 5). In $\mathrm{Ca}^{2+} / \mathrm{Mg}^{2+}$ free medium anti- $\alpha \mathrm{v}$ integrin $\mathrm{mAb}$ did not affect DC migration toward OPN, while antiCD44 mAb IM7 (Fig. 5) and KM81 (data not shown) inhibited OPN-induced migration. In $\mathrm{Ca}^{2+} / \mathrm{Mg}^{2+}$ containing medium, both anti- $\alpha \mathrm{v}$ integrin and anti-CD44 mAbs blocked DC migration (Fig. 5). Combination of antiCD44 and $\alpha \mathrm{v}$ mAbs resulted in a complete block of DC

Table I. OPN Induces Chemotactic DC Migration

\begin{tabular}{lccc}
\hline & \multicolumn{3}{c}{ Number of migrated cells } \\
\cline { 2 - 4 } & \multicolumn{3}{c}{ Upper chamber contents of $(\mu \mathrm{g} / \mathrm{ml})$} \\
$\begin{array}{l}\text { Lower chamber } \\
\text { contents }(\mu \mathrm{g} / \mathrm{ml})\end{array}$ & HBSS & 0.5 OPN & 2.0 OPN \\
\hline HBSS & $155.5 \pm 4.95$ & $178.0 \pm 58$ & $171.5 \pm 17.7$ \\
0.5 OPN & $239.0 \pm 39.6$ & $140.0 \pm 8.5$ & - \\
2.0 OPN & $269.5 \pm 36.1$ & - & $173.0 \pm 2.1$ \\
& & - & - \\
2.0 GST & $97.5 \pm 12.0$ & - &
\end{tabular}

$10^{6}$ cells $/ \mathrm{ml}$ DCs were generated as described in Materials and Methods and applied to the upper chamber of modified Boyden chambers. The chamber was incubated for $4 \mathrm{~h}$ at $37^{\circ} \mathrm{C}$ and cells that had migrated to the lower chamber were evaluated as described in Materials an Methods. Data are shown as cells $/ \mathrm{mm}^{2} \pm \mathrm{SD}$ that had migrated across membranes of triplicate chambers.
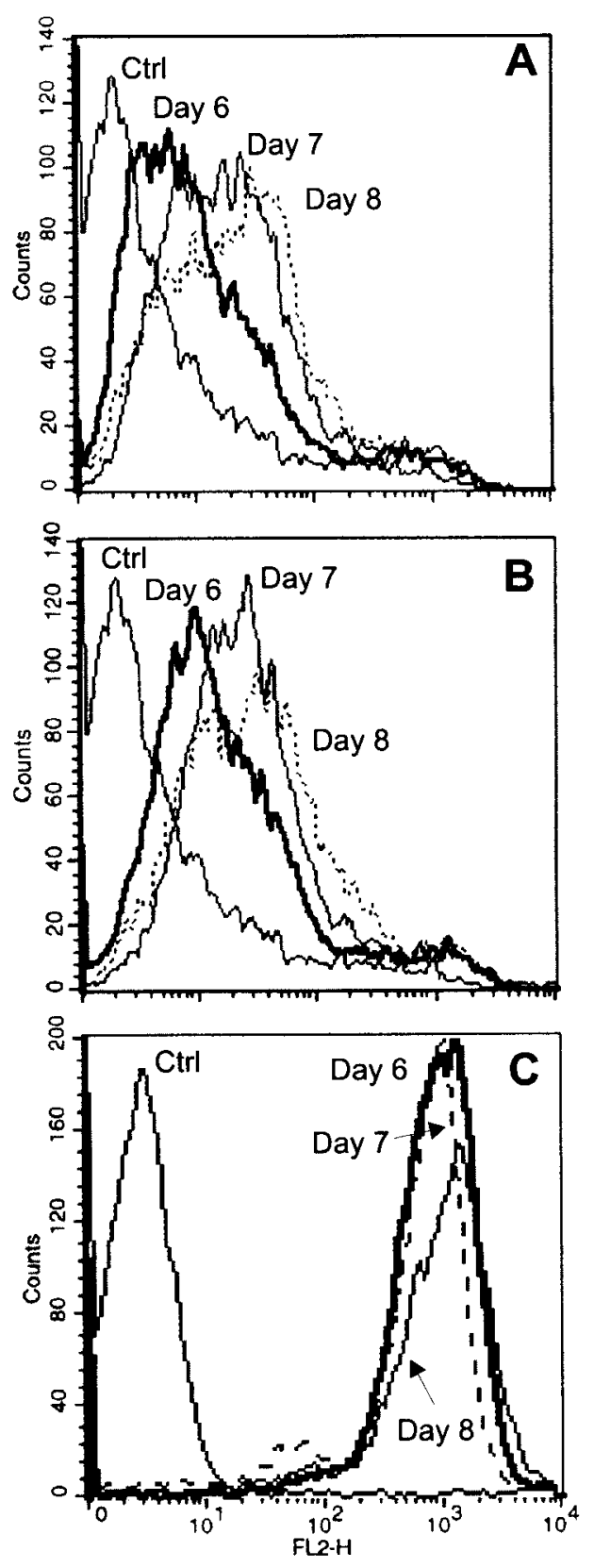

Figure 4. $\quad \alpha v \beta 3$ expression is upregulated during DC maturation. Murine DCs were generated from bone marrow precursors, purified by density gradient as described in Materials and Methods, and stained for FACS $^{\circledR}$ analysis with mAbs against (A) $\alpha \mathrm{v}$ (CD51), (B) $\beta 3$ (CD61, mAb) integrin, or (C) pan CD44 mAb. DC were harvested on days 6,7 , and 8 of DC culture.

migration toward OPN (Fig. 5). Spontaneous chemokinesis or LPS-induced DC migration were not affected by any of the mAbs (data not shown).

Intradermal Injection of OPN Induces LC Migration from the Epidermis. Analysis of LC emigration from epidermal sheets is a well-defined system to study skin DC migration in vivo (41). To confirm a functional role of OPN in LC/ $\mathrm{DC}$ migration in vivo, OPN or appropriate controls were injected into the ear pinnae of mice. After $48 \mathrm{~h}$ ears were 


\begin{tabular}{|c|c|}
\hline Stimulus & mAb \\
\hline \hline GST & - \\
OPN & - \\
OPN & Ctrl \\
OPN & $\alpha v$ \\
OPN & CD44 \\
OPN & CD $44+\alpha v$ \\
\hline
\end{tabular}

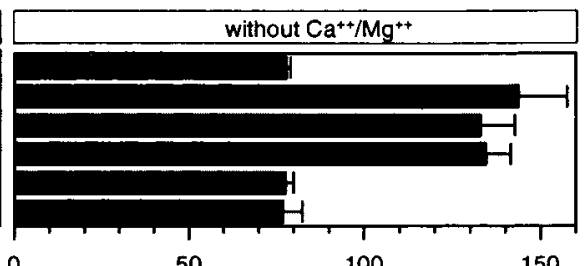

\begin{tabular}{|c|c|}
\hline Stimulus & mAb \\
\hline \hline GST & - \\
OPN & - \\
OPN & Ctrl \\
OPN & $\alpha v$ \\
OPN & CD44 \\
OPN & CD $44+\alpha v$ \\
\hline
\end{tabular}

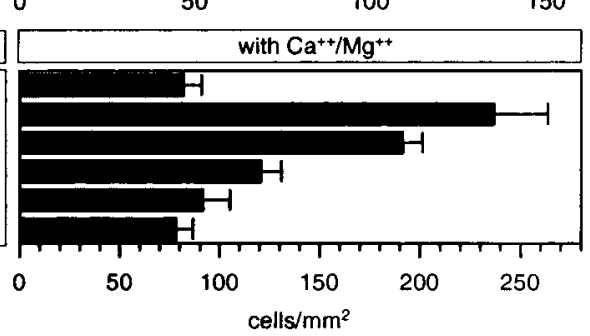

Figure 5. OPN-induced migration of DCs is dependent on CD44 and the $\alpha \mathrm{v}$ integrin subunit on DCs. $10^{6}$ untreated murine DCs or DCs pretreated with $10 \mu \mathrm{g} / \mathrm{ml}$ of control antibody (Y13-259), anti-CD44 mAbs (IM7), or anti- $\alpha \mathrm{V} \mathrm{mAb}$ (RMV7) were added to the upper chamber of modified Boyden chambers in the presence or absence of $\mathrm{Ca}^{2+} / \mathrm{Mg}^{2+}$. In all assays DCs migrated for $4 \mathrm{~h}$ at $37^{\circ} \mathrm{C}$. Data is shown as cells $/ \mathrm{mm}^{2} \pm \mathrm{SD}$ of four chambers.

obtained and LCs within the epidermal sheets were identified by ATPase staining (34; Fig. 6 A). The number of LCs remaining within the epidermis was quantified by microscope. In OPN-injected ears, up to $50 \%$ of LC had left the epidermis after $48 \mathrm{~h}$ (Fig. 6, A and B) indicating that OPN strongly induced DC migration from the epidermis in vivo. In accordance with the in vitro migration experiments this effect could be partially blocked by mAbs against CD44 and $\alpha \mathrm{v}$ (Fig. $6 \mathrm{C}$ ). While anti-CD44 mAb injected simultaneously with OPN almost completely blocked OPN stimulated LC emigration from the skin, the anti- $\alpha \mathrm{v}$ antibody had an inhibitory effect of up to $50 \%$.

OPN Serves a Functional Role in LC-dependent Induction of CHS. To finally test the role of OPN in vivo we investigated the CHS response of mice lacking a functional OPN gene (28). OPN-deficient C57BL/6 mice and wild-type littermates were sensitized epicutaneously to the hapten TNCB on day 0 . Upon challenge with TNCB at the ear on day 5, wild-type mice showed a normal ear swelling response (Fig. 7). However, when the ears of TNCB sensitized OPN-deficient littermates $(-/-)$ were challenged with the hapten, these mice had a significantly reduced ear swelling response 24 and $48 \mathrm{~h}$ after challenge (Fig. 7). Based on these findings we postulated that OPN is of key importance for the capacity of LCs to induce a CHS response against epicutaneously applied haptens.

To exclude that a reduced number of LCs within the skin of OPN $(-/-)$ mice was responsible for the impaired CHS response, the number of LCs within the epidermis of OPNdeficient mice was compared with wild-type littermates by ATPase staining as described in Materials an Methods. No differences in the number and morphology of epidermal LCs was observed (data not shown), demonstrating a normal distribution of LCs in the skin of OPN-deficient mice.
A
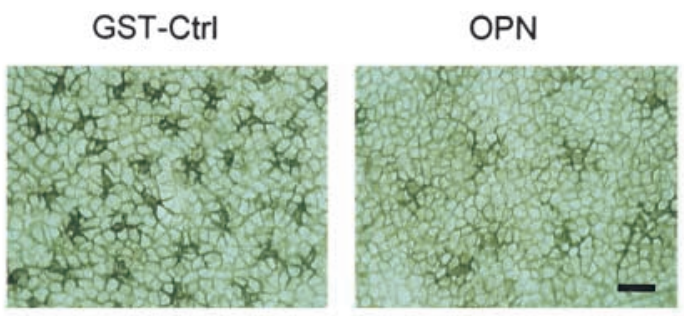

B

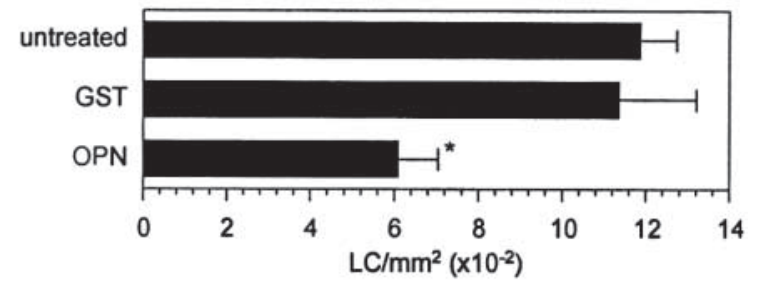

C

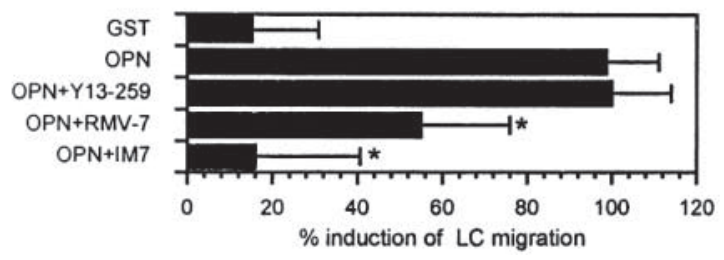

Figure 6. OPN induces emigration of LCs from the epidermis which is partially inhibited by mAbs against CD44 and $\alpha \mathrm{v}$. Groups of three mice were left untreated or injected with either PBS, GST control protein (50 $\mu \mathrm{g} / \mathrm{ml}$ ), or GST-OPN $(50 \mu \mathrm{g} / \mathrm{ml}$ in PBS) into the pinnae of ears (A and B). In panel A epidermal sheets were stained by ATPase histochemistry as described in Materials and Methods. Within the epidermis ATPase is specifically expressed by LCs, stained dendritic LCs appear dark brown (bar $18 \mu \mathrm{m})$. For $\mathrm{mAb}$ blocking experiments, anti-CD44 mAb (IM7), $\alpha \mathrm{v}$ (RMV7), or isotype-matched control antibodies (all $10 \mu \mathrm{g} / \mathrm{ml}$ ) were added to the volume injected (C). Ears were removed after $48 \mathrm{~h}$, epidermal sheets were prepared and stained for ATPase expression, and LC/ $\mathrm{mm}^{2}$ were counted by microscope as described in Materials and Methods. * = statistically significant at $P<0.05$, one way analysis of variance (ANOVA), Student-Newmann-Keuls test of four ears. Percent induction was calculated by defining the number of LCs in untreated ears as $0 \%$.

We now addressed whether the reduced migration of DCs is responsible for the altered CHS response by using an established model to detect the number of LCs/DCs that migrate from the skin to regional draining lymph nodes during the sensitization phase of CHS (35). The hapten FITC was applied to the skin of abdomen and thorax of $\mathrm{OPN}^{-/-}$and $\mathrm{OPN}^{+/+}$mice and the number of FITC/ CD11c double-positive cells that had entered the lymph node $48 \mathrm{~h}$ after hapten application was analyzed (35). In $\mathrm{OPN}^{-/-}$mice we found a strongly reduced number of

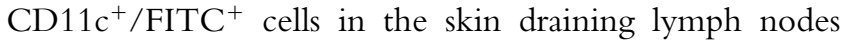
compared with $\mathrm{OPN}^{+/+}$littermates (Fig. $8 \mathrm{~A}$ ).

To further underline the role of OPN in the migration of DCs to lymph nodes a second model was used (30). DCs were generated from wild-type $(+/+)$ littermates of OPN mutant mice $(-/-)$ were fluorescently labeled with $\mathrm{PKH}-2$ and injected into the abdominal skin of wild-type and OPN-deficient mice. Interestingly, up to $75 \%$ less wild- 


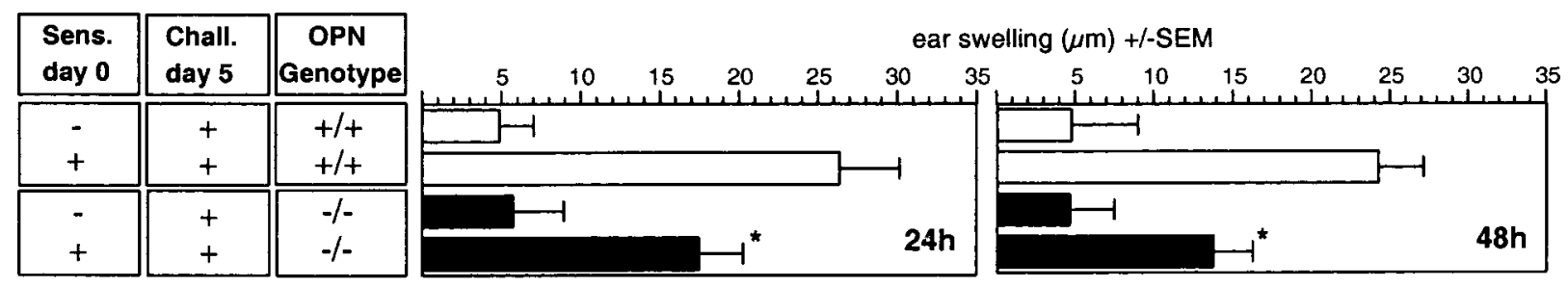

Figure 7. OPN-deficient mice have a reduced CHS-response to TNCB. In OPN null mutant mice and wild-type litter mates CHS was induced as described in Materials and Methods. *Statistically significant reduction of ear swelling at $P<0.001$ (one way ANOVA, Dunnett's test). Each bar represents mean ear swelling data pooled from four animals measured 24 and $48 \mathrm{~h}$ after challenge. Representative of three independent experiments is shown.

type DCs entered the axillary and inguinal lymph nodes when injected into the OPN-deficient $(-/-)$ animals (Fig. $8, \mathrm{~B}$ and $\mathrm{C}$ ). These findings indicate that OPN is of functional importance for the attraction of DC to enter into regional lymph nodes, and therefore plays a key role in the induction of CHS.

\section{Discussion}

In the present work we focused on the function of OPN during the sensitization phase of CHS which crucially depends upon the migration of hapten-carrying LCs/DCs from the epidermis via lymphatic vessels to regional draining lymph nodes. Here we demonstrate that OPN is an important chemotactic factor for DC that guides LCs/DCs from the periphery to regional lymphatic organs.

OPN is a migration inducing factor in several cell systems, e.g., endothelial cells, smooth muscle cells, fibroblasts, lymphocytes, and macrophages $(14,21,22,42)$. In inflammatory responses, invading macrophages are attracted to sites of high OPN expression, i.e., in tubulointerstitial nephrotic disease, myocardial infarction, and response to bacterial infection or skin wounds $(11,28,38,43)$. We found that LCs migrating from the epidermis predominantly traffic toward the highly OPN expressing area of the papillary microvascular dermal plexus. In OPN-rich areas LCs line up to form the characteristic cord-like structures within lymphatics. Furthermore, after the application of the contact allergen TNCB on murine skin we found that OPN mRNA is upregulated in the skin as well as in lymph nodes draining the skin beginning as early as $12 \mathrm{~h}$ after treatment.

Based on our finding that OPN is upregulated in tissues traversed by DCs, we investigated the role of OPN in DC trafficking. We found that OPN induces chemotactic DC migration in microchamber assays. Most significantly, in vivo LC emigration from the epidermis was initiated by in-
A

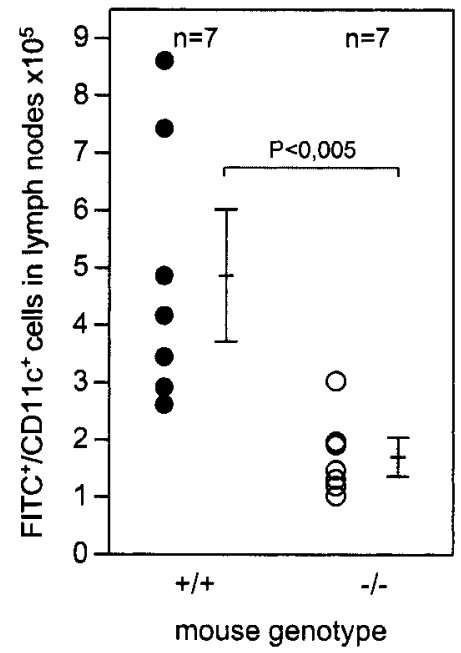

B

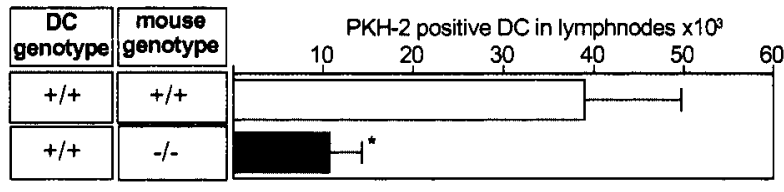

C

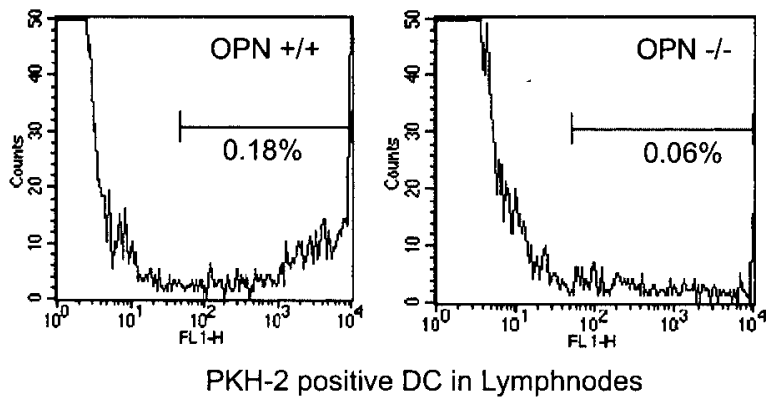

Figure 8. OPN mutant mice have a reduced capacity to attract DCs into lymph nodes draining the skin. (A) Change in the number of $\mathrm{CD}_{11 \mathrm{c}^{+}} / \mathrm{FITC}^{+}$ DCs in lymph nodes analyzed $48 \mathrm{~h}$ after painting of $2 \mathrm{mg}$ FITC dissolved in a 50:50 ( $\mathrm{vol} / \mathrm{vol})$ acetone dibutylphtalate (BDH) mixture on the skin of thorax and abdomen of OPN wild-type $(+/+)$ or OPN mutant mice $(-/-)$. Lymph node single cell suspensions were prepared from pooled axillary and inguinal lymph nodes and the number of

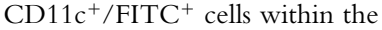
lymph nodes was evaluated by FACS $^{\circledR}$ analysis, as described in Materials and Methods. One dot represents the number of $\mathrm{CD}_{11 \mathrm{c}^{+} / \mathrm{FITC}^{+} \text {cells in pooled }}$ axillary and inguinal lymph nodes of one mouse. Bars indicate the mean \pm SEM of seven mice. The difference in the two groups was statistically significant (paired $t$ test, $P<0,005$ ). A representative of three independent experiments is shown. (B) PKH-2 labeled wild-type $(+/+)$ DCs were injected into the abdominal skin of wildtype $(+/+)$ or OPN mutant mice $(-/-)$. After $20 \mathrm{~h}$ axillary and inguinal lymph node cells from one animal each were pooled, stained for CD11c, and the total number of PKH-2-positive DCs was analyzed by FACS ${ }^{\circledR}$ as described in Materials and Methods. *Statistically significant reduction of PKH-2positive DCs in LNs of OPN ${ }^{-1-}$ mice compared with DCs in LN of $+/+$ mice $(P<0.03$ one way ANOVA, Student-Newmann-Keuls test). Each bar represents the mean \pm SEM from three independent experiments. (C) FACS $^{\circledR}$ analysis of PKH-2 (FL-1) positive cells in pooled axillary and inguinal lymph nodes from one mouse $20 \mathrm{~h}$ after injection of PKH-2-positive DCs into abdominal skin. Bars represent percent of $\mathrm{PKH}-2^{+}$measured lymph node cells. A representative of three independent experiments is shown. 
tradermal OPN injection. These findings strongly argue that upregulation of OPN in sensitized skin is relevant in guiding DCs into the dermis on their path to draining lymph nodes. Several OPN producing cell types are located within the dermis. Dermal fibroblasts, lymphocytes, macrophages, and vascular and lymphatic endothelial cells (44) could all produce OPN after antigenic challenge, leading to chemokine-like attraction of DCs. Here we found that OPN is especially expressed in the vicinity of papillary plexus endothelial cells. Due to a lack of available specific markers for lymphatic endothelial cells we cannot yet determine whether OPN is secreted both by microvascular endothelial cells and by the lymphatic endothelium. However, secretion of chemotactic OPN by microvascular endothelial cells could also lead to an attraction of DCs toward the lymphatics, which closely accompany the capillaries of the microcvascular plexus. By now we can only speculate which factors could be involved in the upregulation of OPN within the skin during the sensitization phase of CHS. Two possible candidates secreted upon hapten challenge of the skin are $\mathrm{TNF}-\alpha$, secreted by keratinocytes and IL-1 $\beta$, secreted by LCs. Both provide important signals in the LC migration from the epidermis (45).

In CHS another potential source of OPN production are cells within draining lymph nodes (10). Beginning at $12 \mathrm{~h}$ after sensitization we found that OPN mRNA is upregulated in lymph nodes draining the skin and OPN protein expression is upregulated in the $\mathrm{T}$ cell areas of draining lymph nodes. Here activated $\mathrm{T}$ cells and macrophages are prime candidates for OPN production $(17,46)$. We speculated that OPN produced by lymph node cells could attract DCs to migrate to these sites. We therefore would like to propose a model in which OPN secreted in lymph nodes, e.g., by activated $\mathrm{T}$ cells could attract DCs to lymph nodes. Different OPN functions might be responsible for the chemoattractive OPN effect on DCs in vivo. The injected OPN may form soluble gradients within the tissue, thereby attracting the DCs to traffic toward OPN. Furthermore, in vitro it has been shown that as an ECM component, OPN interacts with collagen I, II, III, and IV $(18,19)$ and fibronectin $(18,20)$. One may speculate that also in vivo ECM-bound OPN could form a gradient-like path to guide DCs through tissues.

Having identified a chemotactic function of OPN in DC migration we investigated OPN receptors on DCs mediating this function. Two OPN receptors, $\alpha v \beta 3$ and CD44 have been especially associated with OPN-induced cell migration $(21,23,24,39)$. Here we characterized the expression of $\alpha v \beta 3$ on DCs and found that DCs upregulate both the $\alpha \mathrm{v}$ and $\beta 3$ integrin subunits upon maturation in bone marrow cultures, while CD44 was constitutively expressed. By modulating divalent cation concentrations in the presence or absence of blocking $\alpha \mathrm{v}$ and CD $44 \mathrm{mAbs}$ we found that both $\alpha_{\mathrm{v}}$ integrin and CD44 are functionally involved in OPN-induced DC migration in microchamber migration assays. These findings are relevant for DC migration in vivo. Applying LC migration assays in murine ear sheets (41), anti- $\alpha \mathrm{V}$ and anti-CD44 $\mathrm{mAb}$ (recognizing the stan- dard epitope of CD44) partially blocked LC emigration from the epidermis. We cannot exclude that other OPN binding integrins, i.e., $\alpha v \beta 1, \alpha v \beta 5$ are involved in OPNmediated DC migration. However, it was previously demonstrated that migration of human smooth muscle cells depends on $\alpha v \beta 3$, but not on the OPN binding integrins $\alpha v \beta 1$ and $\alpha v \beta 5$ (22).

We previously investigated the expression and function of CD44 splice variants on LCs/DCs (25) and demonstrated that LCs/DCs constitutively express the standard epitope of CD44 (CD44s, pan CD44, common to all CD44 expressing cells) and epitopes formed jointly by CD44v7/8. Upon activation CD44 epitopes encoded by exons v4, v5, v6, and v9 are upregulated on LCs/DCs. These epitopes are especially involved in the migration of these cells from the epidermis, their adhesion in lymph nodes, and the induction of CHS (25). The data shown here support the notion that CD44 is involved in mediating the migration-inducing effects of OPN, as OPNinduced DC migration in Boyden chambers and LC migration from the skin could be blocked by mAbs IM7 and KM81 directed against the standard epitope of CD44 (CD44s, panCD44) (25). Based on our data we cannot tell at present to what extent different CD44 variant isoforms are involved in LC/DC interactions with OPN. However, in Boyden chamber migration assays mAbs against CD44v4 (9A4) or v6 (10D1) (25) were without effect on OPN mediated DC migration (data not shown). This does not rule out that CD44 variant encoded isoforms are involved in DC migration. However, it indicates that the antibodies IM7 and KM81 recognize a CD44 epitope essential for OPN activity. Our work is in accordance with the results of Weber et al. who demonstrated that the anti-CD44 mAb KM81 inhibited OPN-induced migration of CD44transfected A31 murine fibroblasts (transfected with a cDNA containing exons v7 through v10) and the CD44expressing T cell hybridoma AF3.G7 (which likely express a CD44 variant of $\sim 115 \mathrm{kD})(23,47)$. Furthermore, other studies demonstrated that CD44 variants cooperate with $\beta 1$-containing integrins to bind to OPN to stimulate chemotaxis of tumor cells (24). Based on these studies and the work presented here it remains to be defined exactly which CD44 isoforms are able to interact with OPN on DCs and whether other molecules such as $\beta 1$ integrin are involved. Recently it was demonstrated that CD44-hIg fusion proteins did not bind to different forms of human OPN (48). These findings are in contrast to other reports that demonstrated binding of OPN to CD44 expressed in murine fibroblast cell lines and $\mathrm{T}$ cell hybridomas (23). In this study we did not investigate OPN binding interactions with CD44 on LCs/DCs. However, we clearly demonstrate that OPN-induced migration is blocked by two different mAbs against CD44s (IM7 and KM81). To what extent the $\beta 1-$ integrin subunit is involved in this mechanism must be the subject of further investigation.

The ultimate test for the role of OPN in CHS is to examine the ability of OPN-deficient mice to mount an appropriate CHS response to an epicutaneously applied hap- 
ten. Indeed we found that OPN null mutant mice had a significantly reduced CHS response to TNCB. These findings complement previous studies with OPN mutant mice that have demonstrated a severely impaired cell-mediated immunity to viral and bacterial infections and a reduced development of sarcoid type granulomas $(16,17)$. This test, however, does not yet demonstrate that the impaired cellmediated immune response is due to a reduced migration of LCs/DCs. Having excluded that OPN-deficient mice have a reduced number of LCs in the epidermis we used two different established approaches to further prove this concept $(30,35)$. When FITC was painted on abdominal skin, we found significantly less $\mathrm{FITC}^{+} / \mathrm{CD} 11 \mathrm{c}^{+}$cells within the draining lymph nodes of OPN-deficient mice $48 \mathrm{~h}$ after FITC application. Furthermore, when we injected wildtype DCs into OPN-deficient mice up to 75\% less DCs were attracted into lymph nodes of OPN-deficient mice. These experiments clearly demonstrates an impaired migratory function of DCs in the absence of OPN. However, we cannot exclude that other OPN functions responsible for the migration of $\mathrm{T}$ cells or macrophages into inflammatory sites are additionally affecting the reduced CHS ear swelling response in OPN mutant mice after hapten challenge.

In summary, our findings provide evidence that OPN upregulated in the skin and draining lymph nodes during the sensitization phase of CHS is a chemotactic protein for LCs/DCs. Pro-migratory OPN effects on DCs are mediated by at least two OPN receptors, CD44 and an $\alpha \mathrm{v}$-containing integrin. Interestingly, mice deficient in OPN production have a reduced CHS response. This effect is likely to be due to a reduced migratory capacity of DCs in OPN mutant mice. Our data indicates that OPN function in directed migration of DCs from the periphery to regional lymph nodes is an important event in DC-mediated delayed type hypersensitivity.

We thank Käthe Thoma, Christine Bernardi, Thies Eggers, and Sylke Lange for expert technical assistance. We thank Jonathan Sleeman for fruitful discussions and review of the manuscript, and Horst Mossmann for extremely valuable help with the backcrossing of the OPN-deficient mice.

This work was supported by a grant from the Deutsche Forschungsgemeinschaft (DFG WE-1919/2-1)

Submitted: 20 October 2000

Revised: 26 July 2001

Accepted: 6 September 2001

\section{References}

1. Banchereau, J., and R.M. Steinman. 1998. Dendritic cells and the control of immunity. Nature. 392:245-252.

2. Austyn, J.M. 1996. New insights into the mobilization and phagocytic activity of dendritic cells. J. Exp. Med. 183:12871292.

3. Hart, D.N. 1997. Dendritic cells: unique leukocyte populations which control the primary immune response. Blood. 90: 3245-3287.

4. Schuler, G., F. Koch, C. Heufler, E. Kampgen, G. Topar, and N. Romani. 1993. Murine epidermal Langerhans cells as a model to study tissue dendritic cells. Adv. Exp. Med. Biol. 329:243-249.

5. Kripke, M.L., C.G. Munn, A. Jeevan, J.M. Tang, and C. Bucana. 1990. Evidence that cutaneous antigen-presenting cells migrate to regional lymph nodes during contact sensitization. J. Immunol. 145:2833-2838.

6. Kimber, I., R.J. Dearman, M. Cumberbatch, and R.J.D. Huby. 1998. Langerhans cells and chemical allergy. Curr. Opin. Immunol. 10:614-619.

7. Kimber, I., M. Cumberbatch, R.J. Dearman, M. Bhushan, and C.E. Griffiths. 2000. Cytokines and chemokines in the initiation and regulation of epidermal Langerhans cell mobilization. Br. J. Dermatol. 142:401-412.

8. Uede, T., Y. Katagiri, J. Iizuka, and M. Murakami. 1997. Osteopontin, a coordinator of host defense system: a cytokine or an extracellular adhesive protein? Microbiol. Immunol. 41:641-648.

9. O’Regan, A.W., G.J. Nau, G.L. Chupp, and J.S. Berman. 2000. Osteopontin (Eta-I) in cell mediated immunity: teaching an old dog new tricks. Immunol. Today. 21:475-478.

10. Cantor, H. 1995. The role of Eta-1/osteopontin in the pathogenesis of immunological disorders. Ann. NY. Acad. Sci. 760:143-150.

11. Patarca, R., G.J. Freeman, R.P. Singh, F.Y. Wei, T. Durfee, F. Blattner, D.C. Regnier, C.A. Kozak, B.A. Mock, and H.C. Morse III. 1989. Structural and functional studies of the early T lymphocyte activation 1 (Eta-1) gene. Definition of a novel $\mathrm{T}$ cell-dependent response associated with genetic resistance to bacterial infection. J. Exp. Med. 170:145-161.

12. Giachelli, C.M., D. Lombardi, R.J. Johnson, C.E. Murry, and M. Almeida. 1998. Evidence for a role of osteopontin in macrophage infiltration in response to pathological stimuli in vivo. Am. J. Pathol. 152:353-358.

13. Pollack, S.B., P.A. Linnemeyer, and S. Gill. 1994. Induction of osteopontin mRNA expression during activation of murine NK cells. J. Leukoc. Biol. 55:398-400.

14. O'Regan, A.W., G.L. Chupp, J.A. Lowry, M. Goetschkes, N. Mulligan, and J.S. Berman. 1999. Osteopontin is associated with $\mathrm{T}$ cells in sarcoid granulomas and has $\mathrm{T}$ cell adhesive and cytokine-like properties in vitro. J. Immunol. 162: 1024-1031.

15. Nau, G.J., P. Guilfoile, G.L. Chupp, J.S. Berman, S.J. Kim, H. Kornfeld, and R.A. Young. 1997. A chemoattractant cytokine associated with granulomas in tuberculosis and silicosis. Proc. Natl. Acad. Sci. USA. 94:6414-6419.

16. Nau, G.J., L. Liaw, G.L. Chupp, J.S. Berman, B.L. Hogan, and R.A. Young. 1999. Attenuated host resistance against mycobacterium bovis BCG infection in mice lacking osteopontin. Infect. Immun. 67:4223-4230.

17. Ashkar, S., G.F. Weber, V. Panoutsakopoulou, M.E. Sanchirico, M. Jansson, S. Zawaideh, S.R. Rittling, D.T. Denhardt, M.J. Glimcher, and H. Cantor. 2000. Eta-1 (Osteopontin): An early component of type-1 (Cell-mediated) immunity. Science. 287:860-864.

18. Kaartinen, M.T., A. Pirhonen, A. Linnala-Kankkunen, and P.H. Maenpaa. 1999. Cross-linking of osteopontin by tissue transglutaminase increases its collagen binding properties. $J$. Biol. Chem. 274:1729-1735.

19. Butler, W.T. 1995. Structural and functional domains of osteopontin. Ann. NY. Acad. Sci. 760:6-11.

20. Mukherjee, B.B., M. Nemir, S. Beninati, E. Cordella-Miele, K. Singh, I. Chackalaparampil, V. Shanmugam, M.W. DeVouge, and A.B. Mukherjee. 1995. Interaction of osteopon- 
tin with fibronectin and other extracellular matrix molecules. Ann. NY. Acad. Sci. 760:201-212.

21. Senger, D.R., S.R. Ledbetter, K.P. Claffey, A. Papadopoulos-Sergiou, C.A. Peruzzi, and M. Detmar. 1996. Stimulation of endothelial cell migration by vascular permeability factor/vascular endothelial growth factor through cooperative mechanisms involving the alphavbeta3 integrin, osteopontin, and thrombin. Am. J. Pathol. 149:293-305.

22. Liaw, L., M.P. Skinner, E.W. Raines, R. Ross, D.A. Cheresh, S.M. Schwartz, and C.M. Giachelli. 1995. The adhesive and migratory effects of osteopontin are mediated via distinct cell surface integrins. Role of alpha $\mathrm{v}$ beta 3 in smooth muscle cell migration to osteopontin in vitro. J. Clin. Invest. 95:713-724.

23. Weber, G.F., S. Ashkar, M.J. Glimcher, and H. Cantor. 1996. Receptor-ligand interaction between CD44 and Osteopontin (Eta-1). Science. 271:509-512.

24. Katagiri, Y.U., J. Sleeman, H. Fujii, P. Herrlich, H. Hotta, K. Tanaka, S. Chikuma, H. Yagita, K. Okumura, M. Murakami, et al. 1999. CD44 variants but not CD44s cooperate with beta1-containing integrins to permit cells to bind to osteopontin independently of arginine-glycine-aspartic acid, thereby stimulating cell motility and chemotaxis. Cancer Res. 59:219-226.

25. Weiss, J.M., J. Sleeman, A.C. Renkl, H.C. Dittmar, C.T. Termeer, S. Taxis, N. Howells, M. Hofmann, G. Köhler, E. Schöpf, et al. 1997. An essential role for CD44 variant isoforms in epidermal Langerhans cell and blood dendritic cell function. J. Cell Biol. 137:1137-1147.

26. Craig, A.M., J.H. Smith, and D.T. Denhardt. 1989. Osteopontin, a transformation-associated cell adhesion phosphoprotein, is induced by 12-O-tetradecanoylphorbol 13acetate in mouse epidermis. J. Biol. Chem. 264:9682-9689.

27. Katagiri, Y.U., M. Murakami, K. Mori, J. Iizuka, T. Hara, K. Tanaka, W.Y. Jia, A.F. Chambers, and T. Uede. 1996. NonRGD domains of osteopontin promote cell adhesion without involving alpha v integrins. J. Cell. Biochem. 62:123-131.

28. Liaw, L., D.E. Birk, C.B. Ballas, J.S. Whitsitt, J.M. Davidson, and B.L. Hogan. 1998. Altered wound healing in mice lacking a functional osteopontin gene (spp1). J. Clin. Invest. 101: $1468-1478$.

29. Inaba, K., M. Inaba, N. Romani, H. Aya, M. Deguchi, S. Ikehara, S. Muramatsu, and R.M. Steinman. 1992. Generation of large numbers of dendritic cells from mouse bone marrow cultures supplemented with granulocyte/macrophage colony-stimulating factor. J. Exp. Med. 176:1693-1702.

30. Lappin, M.B., J.M. Weiss, V. Delattre, B. Mai, H. Dittmar, C. Maier, K. Manke, S. Grabbe, S. Martin, and J.C. Simon. 1999. Analysis of mouse dendritic cell migration in vivo upon subcutaneous and intravenous injection. Immunology. 98:181-188.

31. Kon, S., M. Maeda, T. Segawa, Y. Hagiwara, Y. Horikoshi, S. Chikuma, K. Tanaka, M.M. Rashid, M. Inobe, A.F. Chambers, and T. Uede. 2000. Antibodies to different peptides in osteopontin reveal complexities in the various secreted forms. J. Cell. Biochem. 77:487-498.

32. Sozzani, S., F. Sallusto, W. Luini, D. Zhou, L. Piemonti, P. Allavena, J. Van Damme, S. Valitutti, A. Lanzavecchia, and A. Mantovani. 1995. Migration of dendritic cells in response to formyl peptides, C5a, and a distinct set of chemokines. $J$.
Immunol. 155:3292-3295.

33. Takahashi, K., T. Nakamura, M. Koyanagi, K. Kato, Y. Hashimoto, H. Yagita, and K. Okumura. 1990. A murine very late activation antigen-like extracellular matrix receptor involved in CD2- and lymphocyte function-associated antigen-1-independent killer-target cell interaction. J. Immunol. 145:4371-4379.

34. Mackenzie, I.C., and C.A. Squier. 1975. Cytochemical identification of ATPase-positive langerhans cells in EDTA- separated sheets of mouse epidermis. Br. J. Dermatol. 92:523-533.

35. Macatonia, S.E., S.C. Knight, A.J. Edwards, S. Griffiths, and P. Fryer. 1987. Localization of antigen on lymph node dendritic cells after exposure to the contact sensitizer fluorescein isothiocyanate. Functional and morphological studies. J. Exp. Med. 166:1654-1667.

36. Tokunaga, K., H. Taniguchi, K. Yoda, M. Shimizu, and S. Sakiyama. 1986. Nucleotide sequence of a full-length cDNA for mouse cytoskeletal beta-actin mRNA. Nucleic Acids Res. 14:2829.

37. Hotta, H., S. Kon, Y.U. Katagiri, N. Tosa, T. Tsukamoto, A.F. Chambers, and T. Uede. 1999. Detection of various epitopes of murine osteopontin by monoclonal antibodies. Biochem. Biophys. Res. Commun. 257:6-11.

38. Giachelli, C.M., R. Pichler, D. Lombardi, D.T. Denhardt, C.E. Alpers, S.M. Schwartz, and R.J. Johnson. 1994. Osteopontin expression in angiotensin II-induced tubulointerstitial nephritis. Kidney Int. 45:515-524.

39. Singh, R.P., R. Patarca, J. Schwartz, P. Singh, and H. Cantor. 1990. Definition of a specific interaction between the early $\mathrm{T}$ lymphocyte activation 1 (Eta-1) protein and murine macrophages in vitro and its effect upon macrophages in vivo. J. Exp. Med. 171:1931-1942.

40. Lukas, M., H. Stossel, L. Hefel, S. Imamura, P. Fritsch, N.T. Sepp, G. Schuler, and N. Romani. 1996. Human cutaneous dendritic cells migrate through dermal lymphatic vessels in a skin organ culture model. J. Invest. Dermatol. 106:1293-1299.

41. Price, A.A., M. Cumberbatch, I. Kimber, and A. Ager. 1997. Alpha 6 integrins are required for Langerhans cell migration from the epidermis. J. Exp. Med. 186:1725-1735.

42. Liaw, L., M. Almeida, C.E. Hart, S.M. Schwartz, and C.M. Giachelli. 1994. Osteopontin promotes vascular cell adhesion and spreading and is chemotactic for smooth muscle cells in vitro. Circ. Res. 74:214-224.

43. Giachelli, C.M., L. Liaw, C.E. Murry, S.M. Schwartz, and M. Almeida. 1995. Osteopontin expression in cardiovascular diseases. Ann. NY. Acad. Sci. 760:109-126.

44. Denhardt, D.T., and X. Guo. 1993. Osteopontin: a protein with diverse functions. FASEB J. 7:1475-1482.

45. Cumberbatch, M., R.J. Dearman, and I. Kimber. 1997. Langerhans cells require signals from both tumour necrosis factor-alpha and interleukin-1 beta for migration. Immunology. 92:388-395.

46. Weber, G.F., and H. Cantor. 1996. The immunology of Eta1/osteopontin. Cytokine Growth Factor Rev. 7:241-248.

47. Weber, G.F., S. Ashkar, and H. Cantor. 1997. Interaction between CD44 and osteopontin as a potential basis for metastasis formation. Proc. Assoc. Am. Physicians. 109:1-9.

48. Smith, L.L., B.W. Greenfield, A. Aruffo, and C.M. Giachelli. 1999. CD44 is not an adhesive receptor for osteopontin. $J$. Cell Biochem. 73:20-30. 